\title{
Stage III Chronic Lymphocytic Leukemia
}

National Cancer Institute

\section{Source}

National Cancer Institute. Stage III Chronic Lymphocytic Leukemia. NCI Thesaurus. Code C7876.

Risk: High; Findings: Lymphocytosis and hemoglobin less than $11 \mathrm{~g} / \mathrm{dL}$; Survival (months): 30. (from AJCC 8th Ed.) 